\title{
Solution to trifluoroacetic acid NMR challenge
}

\author{
Marie-Pier Thibeault ${ }^{1} \cdot$ Juris Meija ${ }^{1}$
}

Accepted: 10 May 2021 / Published online: 5 July 2021

(C) Crown copyright in right of Canada 2021

The winner of the trifluoroacetic acid NMR challenge (published in volume 413 issue 1) is:

Irina Ihnatenko, Technische Universität Braunschweig, Germany.

The award entitles the winner to select a Springer book of their choice up to a value of $€ 100,-$.

Our Congratulations!

In a previous Analytical Challenge about phosphine [1, 2], we saw that isotopic labeling brings a new level of complexity to NMR spectra of simple substances. The trifluoroacetic acid NMR challenge [3] invites readers to further explore this aspect of analytical chemistry. To understand the ${ }^{19} \mathrm{~F}-\mathrm{NMR}$ spectrum of carbon-13 labeled trifluoroacetic acid (TFA), one has to consider all the interactions that fluorine-19 atoms can have with carbon-13 atoms, both of which have a nonzero nuclear spin, $I=1 / 2$.

In TFA having only carbon- 12 atoms, $\mathrm{F}_{3}\left[{ }^{12} \mathrm{C}\right]\left[{ }^{12} \mathrm{C}\right] \mathrm{OOH}$, the three equivalent fluorine atoms have no neighboring atoms of non-zero nuclear spin. Thus, such a molecule will display a single resonance with chemical shift in the vicinity of $-76 \mathrm{ppm}$ (relative to $\mathrm{CFCl}_{3}$ ). In the singly labeled TFA, $\mathrm{F}_{3}\left[{ }^{13} \mathrm{C}\right]\left[{ }^{12} \mathrm{C}\right] \mathrm{OOH}$, however, fluorine atoms will interact with the single adjacent carbon-13 giving rise to a doublet with a wide coupling constant $\left({ }^{1} \mathrm{~J}_{\mathrm{FC}}=285 \mathrm{~Hz}\right)$ as shown in Fig. 1 . Similarly for the other singly labeled TFA, $\mathrm{F}_{3}\left[{ }^{12} \mathrm{C}\right]\left[{ }^{13} \mathrm{C}\right] \mathrm{OOH}$, fluorine atoms will interact with carbon- 13 two bonds away, leading to a doublet albeit with much smaller coupling con$\operatorname{stant}\left({ }^{2} J_{\mathrm{FC}}=45 \mathrm{~Hz}\right)$ [4]. These two NMR spectra are depicted in Fig. 2.

Finally, in the doubly labeled TFA, $\mathrm{F}_{3}\left[{ }^{13} \mathrm{C}\right]\left[{ }^{13} \mathrm{C}\right] \mathrm{OOH}$, fluorine atoms will interact with both cabon-13 atoms. First, the three equivalent fluorine atoms are coupling with the adjacent carbon-13 atom giving rise to a wide doublet $\left({ }^{1} J_{\mathrm{FC}}\right)$. But, in addition, this doublet is further split into doublets because the same fluorine atoms also interact with the distant carbon-13 atom $\left({ }^{2} J_{\mathrm{FC}}\right)$ [5]. The result of this double splitting leads to a doublet of doublets with a wide first split and a much narrower second split as shown in Fig. 2 (corresponding to Fig. 1A of the trifluoroacetic acid NMR challenge [3]).

This article is the solution to the Analytical Challenge to be found athttps://doi.org/10.1007/s00216-020-02867-3

Juris Meija

juris.meija@nrc-cnrc.gc.ca

1 National Research Council Canada, Ottawa, ON K1A 0R6, Canada 


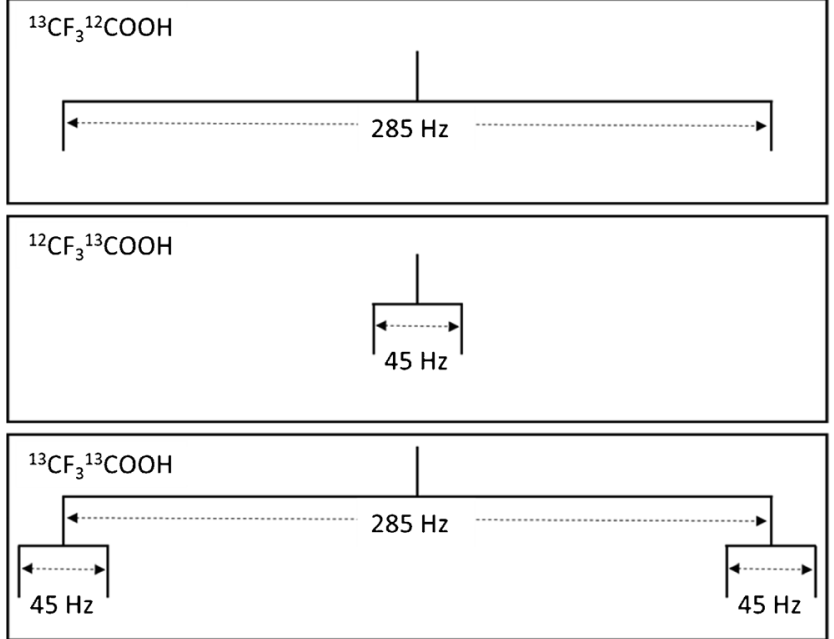

Fig. 1 Signal splitting patterns illustrating the ${ }^{19} \mathrm{~F}-\mathrm{NMR}$ spectra of carbon-13 labeled trifluoroacetic acids
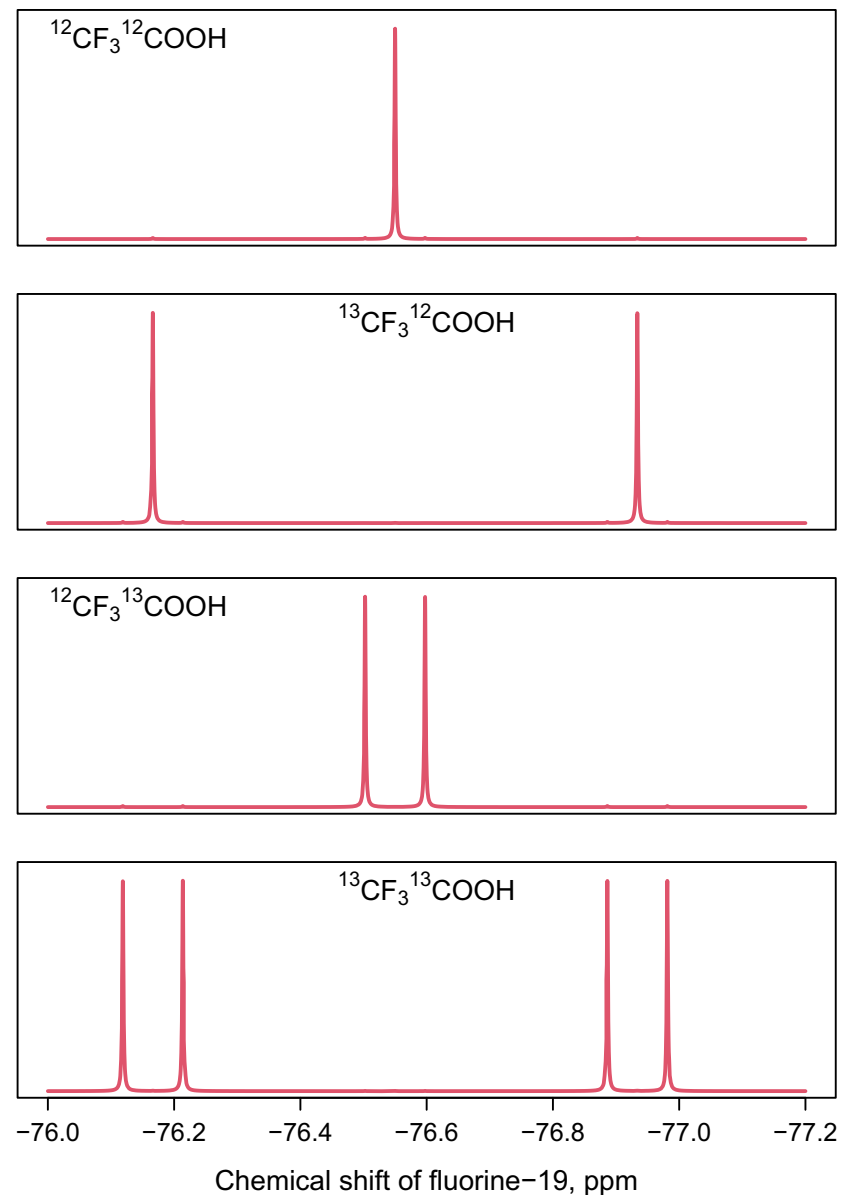

Fig. $2{ }^{19}$ F-NMR spectra of carbon-13 labeled trifluoroacetic acids

\section{Declarations}

Conflict of interest The authors declare no competing interests.

\section{References}

1. Borys A. Phosphine NMR challenge. Anal Bioanal Chem. 2020;412:6633-4.

2. Borys A. Solution to phosphine NMR challenge. Anal Bioanal Chem. 2021:413:2281.

3. Thibeault M-P, Meija J. Trifluoroacetic acid NMR challenge. Anal Bioanal Chem. 2021;413:1-2.

4. Dolbier WR. An overview of fluorine NMR, in guide to fluorine NMR for organic chemists. Hoboken: John Wiley \& Sons, Inc.; 2009. https://doi.org/10.1002/9780470483404.ch2.

5. Valiulin R. NMR multiplet interpretation: an infographic walkthrough: De Gruyter; 2019. https://doi.org/10.1515/9783110608403.

Publisher's note Springer Nature remains neutral with regard to jurisdictional claims in published maps and institutional affiliations. 